\title{
Disease and Diagnosis
}

\section{Prevalence of Surgical Site Infection in Patients With Femoral Shaft Fracture}

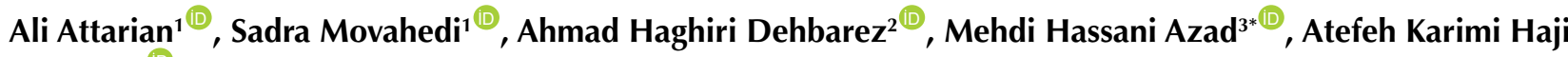 \\ Khademi $^{10}$ \\ ${ }^{1}$ Clinical Research Development Center of Shahid Mohammadi Hospital, Hormozgan University of Medical Sciences, \\ Bandar Abbas, Iran. \\ ${ }^{2}$ Department of Emergency Medicine, Shahid Mohammadi Hospital, Hormozgan University of Medical Sciences, Bandar \\ Abbas, Iran. \\ ${ }^{3}$ Infectious and Tropical Diseases Research Center, Hormozgan Health Institute, Hormozgan University of Medical \\ Sciences, Bandar Abbas, Iran. \\ ${ }^{4}$ Department of Psychology, Hormozgan University of Medical Sciences, Bandar Abbas, Iran.
}

\begin{abstract}
Background: The surgical site infections (SSIs) associated with orthopedic surgeries are prevalent since the commonly used implantation techniques increase the risk of infection. This study aimed to evaluate the prevalence of SSI in patients with femoral shaft fracture (FSF).

Materials and Methods: This retrospective cross-sectional study was performed on patients with FSF referred to Shahid Mohammadi hospital of Bandar Abbas, Iran from 2012 to 2016 for open intramedullary nailing (IMN) of the femoral shaft. Data were entered into the SPSS software version 25.0 for statistical analysis.

Results: Sixty-two individuals with the mean age of $26.95 \pm 1.19$ years participated in the study, of whom $85.5 \%$ were male and $14.5 \%$ were female. Twelve patients $(19.4 \%)$ had open fractures and $50(80.6 \%)$ had closed FSFs. SSI was observed in eight cases, one of whom had deep SSI (osteomyelitis). Our results showed that SSI was not correlated with age or sex $(P<0.05)$, but it was significantly correlated with the frequency of hospitalizations, fractures in other areas, and the type of fracture (open and closed) $(P<0.05)$.

Conclusion: The overall prevalence of SSI was $12.9 \%$, which was higher compared to previous studies. Humidity and warm weather can be major contributing factors to the high prevalence of post-operative infection in this treatment center; however, the conditions of the orthopedic operating room and facilities should also be considered.

Keywords: Femur, Fracture, Nailing, Orthopedic, Surgical site infection
\end{abstract}

\author{
*Correspondence to \\ Mehdi Hassani Azad, \\ Infectious and Tropical \\ Diseases Research Center, \\ Hormozgan Health Institute, \\ Hormozgan University of \\ Medical Sciences, Bandar \\ Abbas, Iran. \\ Tel: 00989177611614, \\ Email:mahdihassaniazad@ \\ gmail.com
}

Received: July 12, 2020, Accepted: December 28, 2020, ePublished: March 30, 2021

\section{Introduction}

Postoperative infection, especially in fracture surgery, has been one of the major problems in the field of orthopedics and has severely affected the outcomes of surgery (1). Despite recent efforts in the field of medical care for hospitalized patients, controlling infectious complications in patients undergoing surgery is still a major challenge (2), with surgical site infections (SSIs) being the most common infectious complication in surgical ward patients (3). SSI is the second most common clinical infection that accounts for $61 \%$ of the cases (4), and can increase mortality, hospital stay, and costs.

Various factors are involved in the development of SSIs, including implantation, drainage, and the surgical approach. SSI is a term that has been replaced by surgical wound infection since 1992 (5). The Center for Disease Control defines the infection that occurs near the surgical wound 30 days after surgery, or 90 days for prosthetic surgery, as SSI (6). SSI is the third most common type of infection health care providers impose to patients (7). Furthermore, SSI implies a decrease in quality of life, a doubling of readmission, prolonged hospital stays, and increased hospital costs (6). In addition, $77 \%$ of deaths from surgical operations have been reported to be infectious, and the infection has a direct association with open surgical wounds (8). US Centers for Disease Control reported that although infection control practices including improved operating room ventilation, sterilization procedures, surgical techniques, and availability of disinfectants are in progress, SSI is one of the major causes of complications, prolonged hospitalization, and death (6).

Among SSI cases, those associated with orthopedic surgeries are important and the most common types for

(C) 2021 The Author(s). This is an open access article distributed under the terms of the Creative Commons Attribution License (http:// creativecommons.org/licenses/by/4.0/), which permits unrestricted use, distribution, and reproduction in any medium, provided the original work is properly cited. 
two reasons: first, implants are commonly used in these surgeries which increase the risk of infection (9); and the second is the anatomical characteristics of the bone. Bone is among the most anemic tissues in the body; therefore, some types of orthopedic surgeries are more susceptible to SSI (10), Although orthopedic surgery is considered a clean surgery and aseptic principles are strictly observed in this type of surgery, SSI is still one of the major complications of this type of surgery. Orthopedic surgical infection occurs in 1\%-3\% of patients undergoing surgery (11).

Since the prevalence of SSI in patients with femoral shaft fracture (FFS) has not been studied in south of Iran so far, in this study, researchers investigated the prevalence of SSI in patients with FFS treated with open intramedullary nailing (IMN) method at Shahid Mohammadi hospital in Bandar Abbas, Iran, between 2012 and 2016.

\section{Materials and Methods}

Following the approval of the Ethics Committee of Hormozgan University of Medical Sciences, this study was performed as a retrospective descriptive cross-sectional study on patients admitted to Shahid Mohammadi hospital in Bandar Abbas, as the largest educational center of Hormozgan province in southern Iran for open IMN of FSF. Patients were selected using a census sampling method. The study population included all patients with FSF who had been referred to Shahid Mohammadi hospital in Bandar Abbas between 2012 and 2016. Sixty-two patients were included in the study. The required information was extracted from patients' medical files. All radiographs, number of visits, and telephone numbers were also recorded. Duration of hospitalization and readmission due to infection was also assessed. Moreover, in case of readmission, the number of hospitalization days was recorded. Data were entered into SPSS software version 25.0. Qualitative data were described by frequency and percentage, and quantitative data with mean and standard deviation. Quantitative data were analyzed using Kolmogorov-Smirnov test and Fisher exact test, chi-square test, and $t$ test were used to compare the variables. $P$ values $<0.05$ were considered as statistically significant.

\section{Results}

The study population included 62 individuals, of whom $53(85.5 \%)$ were male and $9(14.5 \%)$ were female. The mean age of participants was $26.95 \pm 11.19$ years. Among the participants, 12 (19.4\%) had open fractures and $50(80.6 \%)$ had closed FSF. In addition, 27 (43.5\%) had fractures in other areas and 35 were free from fractures in other areas. SSI was observed in eight cases. Fifty-two patients were not hospitalized for further surgery, 9 were hospitalized once, and 1 was hospitalized twice. In this study, 17 (27.4\%) patients were younger than 20 years, 33 (53.2\%) were $21-30$ years, 7 (11.3\%) were $31-41$ years, and $5(8.1 \%)$ were older than 41 years. In our study, there was one deep SSI case (osteomyelitis). Moreover, three patients had a history of smoking and one had diabetes, none of whom had SSI. The mean duration of antibiotic use, as well as mean hospitalization and ICU duration were $7.44 \pm 5.9,7.73 \pm 5.4$, and $1.44 \pm 2.72$ days, respectively (Table 1).

There was no significant relationship between sex and age, duration of antibiotic use, length of hospitalization, and ICU length of stay $(P<0.05)$. According to Table 2, no significant relationship was found between the type of wound and age and ICU length of stay $(P<0.05)$; but there was a significant relationship between duration of antibiotic use and the length of hospitalization with wound type $(P<0.05)$. Individuals with open fractures had longer antibiotic use and longer hospital stay after first surgery compared to those with closed fractures. According to the findings of Table 2, no significant relationship was found between the fracture variables of other regions with age and ICU length of stay $(P<0.05)$, while antibiotic use and hospital stay had a significant relationship with fracture of other regions $(P<0.05)$. In other words, people with fractures in other areas had longer antibiotic use and longer hospital stay in comparison with others.

Table 3 shows that 4 (out of 12) open fracture cases and 4 (out of 50) closed fracture cases had SSI. There was a statistically significant relationship between the type of wound and SSI, with those with open sores more likely to develop SSI $(P=0.039)$. The prevalence of SSI in our study was $12.9 \%$, and it was not related to age or sex $(P<0.05)$; however, it was significantly correlated with the number of hospital admissions, fractures in other areas, and the type of fracture (open and closed) $(P<0.05)$. Moreover, the number of subsequent hospitalizations was significantly associated with SSI. In other words, those who had more frequent hospitalizations were significantly more likely

Table 1. Descriptive Findings

\begin{tabular}{lcccc}
\hline Variable & Minimum & Maximum & Mean & $\begin{array}{c}\text { Standard } \\
\text { Deviation }\end{array}$ \\
\hline Age & 15 & 68 & 26.95 & 11.197 \\
\hline Duration of antibiotic use & 2 & 30 & 7.44 & 5.955 \\
\hline Duration of hospitalization & 2 & 30 & 7.73 & 5.427 \\
\hline Duration of ICU admission & 0 & 11 & 1.423 & 2.7205 \\
\hline
\end{tabular}

Table 2. Correlation Between Variables

\begin{tabular}{lcccc}
\hline Variable & Gender & $\begin{array}{c}\text { Type of } \\
\text { Wound }\end{array}$ & $\begin{array}{c}\text { Fractures of } \\
\text { Other Areas }\end{array}$ & $\begin{array}{c}\text { Surgical Site } \\
\text { Infection }\end{array}$ \\
\hline Age & 0.071 & 0.481 & 0.483 & 0.814 \\
\hline $\begin{array}{l}\text { Duration of antibiotic } \\
\text { use }\end{array}$ & 0.928 & 0.014 & 0.000 & 0.002 \\
\hline $\begin{array}{l}\text { Duration of } \\
\text { hospitalization }\end{array}$ & 0.356 & 0.016 & 0.000 & 0.000 \\
\hline $\begin{array}{l}\text { Duration of ICU } \\
\text { admission }\end{array}$ & 0.313 & 0.114 & 0.142 & 0.228 \\
\hline
\end{tabular}


Table 3. The Relationship Between Surgical Site Infection and Other Components

\begin{tabular}{|c|c|c|c|c|c|c|c|c|c|c|c|c|c|c|c|c|c|c|c|c|c|c|c|}
\hline & & \multicolumn{4}{|c|}{ Gender } & \multirow{3}{*}{$\begin{array}{c}P \\
\text { Value }\end{array}$} & \multicolumn{4}{|c|}{ Wound Type } & \multirow{3}{*}{$\begin{array}{c}P \\
\text { Value }\end{array}$} & \multicolumn{4}{|c|}{$\begin{array}{c}\text { Fractures of Other } \\
\text { Areas }\end{array}$} & \multirow{3}{*}{$\begin{array}{c}P \\
\text { Value }\end{array}$} & \multicolumn{6}{|c|}{$\begin{array}{c}\text { Number of Previous } \\
\text { Hospitalizations }\end{array}$} & \multirow{3}{*}{$P$ Value } \\
\hline & & \multicolumn{2}{|c|}{ Male } & \multicolumn{2}{|c|}{ Female } & & \multicolumn{2}{|c|}{ Open } & \multicolumn{2}{|c|}{ Closed } & & \multicolumn{2}{|c|}{ Yes } & \multicolumn{2}{|c|}{ No } & & \multicolumn{2}{|c|}{ No record } & \multicolumn{2}{|c|}{ Once } & \multicolumn{2}{|c|}{ Twice } & \\
\hline & & No. & $\%$ & No. & $\%$ & & No. & $\%$ & No. & $\%$ & & No. & $\%$ & No. & $\%$ & & No. & $\%$ & No. & $\%$ & No. & $\%$ & \\
\hline \multirow{3}{*}{$\begin{array}{l}\text { Surgical } \\
\text { site } \\
\text { infection }\end{array}$} & Yes & 8 & 15.1 & 0 & 0 & \multirow{3}{*}{0.262} & 4 & 33.3 & 4 & 8 & \multirow{3}{*}{0.039} & 8 & 29.6 & 0 & 0 & \multirow{3}{*}{0.001} & 5 & 9.6 & 2 & 22.2 & 1 & 100 & \multirow{3}{*}{0.0019} \\
\hline & No & 45 & 84.9 & 9 & 100 & & 8 & 66.7 & 46 & 92 & & 19 & 70.4 & 35 & 100 & & 47 & 90.4 & 7 & 77.8 & 0 & 0 & \\
\hline & Total & 53 & 100 & 100 & 100 & & 12 & 100 & 50 & 100 & & 27 & 100 & 35 & 100 & & 52 & 100 & 9 & 100 & 1 & 100 & \\
\hline
\end{tabular}

to develop SSI $(P=0.019)$. As shown in Table 3, 27 cases had other fractures, 8 (29.6\%) of which had SSI; but none of the other 35 cases (with no fractures at other areas) had SSI. There was a statistically significant relationship between fractures of other regions and SSI. Differently put, people with fractures in other areas were more likely to develop SSI $(P=0.039)$.

\section{Discussion}

In summary, the results of our study showed that duration of antibiotic use and length of hospital stay were significantly correlated with the wound type, fractures of other areas, and SSI in patients with FSF. Moreover, SSI was significantly correlated with the wound type (open or closed), fractures of other areas, and the number of hospitalizations, while it was not correlated with age and sex. The prevalence of SSI in our study population was $12.9 \%$ ( 8 cases). It is also noteworthy that 4 patients (33.3\%) of patients with open wounds had SSI, whereas in patients with closed wound fractures the corresponding percentage was $8 \%$. In addition, $29.6 \%$ of those with fractures in other areas had SSI.

Treatment of hip fractures is an orthopedic issue. There is always a high risk of infection and delayed healing. Given that the femur bears the body weight, this delay causes numerous problems such as vascular thrombosis, disability, high cost of multiple, and long-term treatments (12).

Currently, there are several studies on the causes and prevalence of SSI in Iran. Peivandi et al in Mashhad aimed to evaluate 26 patients between the ages of 16 and 45 years with a mean age of 68 years for 20 months. The frequency of fracture types was 2 and 24 according to Gustilo II and IIIA classifications, respectively. Finally, 2 (7.7\%) patients had SSI; one of these cases was superficial and it was controlled with debridement, irrigation, and antibiotic therapy. Finally, this study concluded that the use of untrimmed implant titanium pin is an appropriate method to treat type II and IIIA open hip fractures (13). In a study conducted by Hojjat et al at Motahari Hospital in Jahrom, the prevalence of infection was reported to be $8.8 \%$. This study also evaluated factors, such as duration of surgery, orthopedic surgery with general and women's surgery, being roommates with infectious patients, the number and types of operations performed in the operating room on the same day, the number of hospitalization days before surgery, and the number of hospitalization days associated with wound infection. However, there was a significant relationship between the duration of surgery, the number of operations performed in the operating room on the same day, and the number of hospitalization days with the rate of wound infection (14). A study in Mashhad conducted by Khajemozafari et al compared the open and closed treatment of hip shaft fractures with locking nails, where 40 patients aged 1850 years (33 males and 7 females with a mean age of 26.3 years) with femoral fracture were studied. Patients were divided into two groups and underwent open and closed surgery and were followed for one year. A single case of infection (osteomyelitis) (5\%) was seen in the open reduction group, but there was no significant difference in statistical analysis (15).

In a retrospective study in 2000 by Nowotarski et al, the results of conversion of the femoral external fixation to IMN were reported in open femoral fractures. In this study, 54 patients with 59 FSF treated with an external fixator and conversion into IMN were evaluated. The mean duration of external fixator use was 7 days and the mean follow-up was 12 months. The prevalence of infection was $1.7 \%$ in this study (16).

A study by Noumi et al in Japan investigated the factors affecting deep infection and non-healing in open femoral fractures that were treated with a closed IMN procedure. In this study, 89 femoral open fractures (88 patients) that were treated urgently or with delay and by locked IMN technique were evaluated from 1988 to 2001 . The following predictive variables were selected for analysis: age, sex, Gustilo type (I + II or III), AO type (A or B + C), fracture site (proximal site + distal site or middle site), duration of IMN method, reamed/unreamed nailing (reamed (R) versus unreamed (UR)), presence of multiple trauma (injury severity score (ISS) $<18$ or ISS $\geq 18$ ), debridement time ( $\leq 6$ hours or $>6$ hours), and floating knee injury. In this study, 5 (5.6\%) fractures developed deep infection, one of which was Gustilo type II fracture and the other four were type III fractures. This study showed that only Gustilo type was associated with the occurrence of deep infection $(P<0.05)(17)$.

The results of a retrospective study conducted by Huntley et al in the United States showed that SSI rates were higher in foot and ankle surgeries (18). Najjar et al conducted a prospective multicenter study to determine 
the risk factors and causes of orthopedic SSI in Jordan. Patients were evaluated 90 days after surgery, and 286 patients from 18 hospitals were studied. They reported that $4.9 \%$ of patients were infected, $4.7 \%$ of patients had clean wounds, and $6 \%$ had infectious wounds. The results showed that type of surgery and length of hospitalization were predictors of SSI (11).

As the shaft fracture is mostly a result of high energy trauma, and especially road traffic accidents, younger people are mostly affected; the average age of our study population approves this issue. Therefore, it seems that the young population of our study may justify the low smoking rate (19), as well as the presence of only one case of diabetes and no history of heart disease in our study population.

Lhowe and Hansen (20) studied 46 open femoral fractures treated with reamed IMN and reported two cases of infection that were better than our findings. However, this study had a smaller sample size, which may justify the lower number of SSIs. In the study by O'Brien et al (21) on 63 patients with open femoral fracture treated with IMN primary reamed, 3 (4.8\%) cases of deep infection were reported in Gustilo type 1, type 2 and type 3 fractures, which is in relation with multiple trauma. In this study, the number of patients was similar to ours; however, in our study, there was one case of deep infection and seven cases of superficial infection. Rutter et al (12) and Williams et al (22) also studied the IMN primary reamed operation and made suggestions similar to the study by O’Brien et al.

In a study by Hojjat et al (14), there was a statistically significant relationship between orthopedic SSI and with the number of hospitalization days and type of fracture (open or closed), which was in agreement with the results of our study. There was also a significant relationship between smoking and SSI in this study. The mean length of stay in this study was $7.20 \pm 4.20$ days, and it was $7.73 \pm 5.427$ days in our study. In this study, the prevalence of orthopedic infection was $8.8 \%$, while it was $12.9 \%$ in our study, and there was a statistically significant relationship between SSI with age (15-40 years) and sex, which was not in line with our findings. The prevalence of infection in this study was also lower than that of our study.

In a study by Khan et al (9), age, smoking, and diabetes were identified as factors contributing to the incidence of infection in orthopedic surgeries. These results were contradictory to the results of our study, which could be due to the younger study population of our study, and thus the low prevalence of diabetes and smoking in our statistical population. Nonetheless, similar to our study, in the study by Azizi et al (19), there was no significant relationship between age and the incidence of SSI following non-emergency clean-up surgery.

As expected, and reported in previous studies, similar to our study, the incidence of postoperative infection is higher in open fractures and in fractures that occur in infected environments. The high incidence of postoperative infection in these fractures has also been emphasized in a study by Kundu et al (23). Moreover, our study found that the prevalence of SSI in patients with open wound was $33.3 \%$, indicating a very high prevalence. Mehdinassab et al (24) compared the two methods of plating and locked bone nailing in femoral fractures and reported that the prevalence of infection was $9.7 \%$, of which $15.9 \%$ were in the plating group and $3.3 \%$ were in the grafting group, which was close to the findings of our study. Brumback and Virkus (25) reported an infection rate of $11 \%$ in type II open fractures along with nailing with bone trimming, which was lower than our study. In a study on 141 patients treated with plating, Riemer et al (26) reported 7\% failure in the equipment, one case of nonunion, and two cases of deep infection, having a significantly lower prevalence of infection than our study.

A major limitation to the current study was the small sample size and its single-center design. Further studies on larger populations with multi-center designs are required to confirm the results of our study.

\section{Conclusion}

In the current study, the prevalence of SSI was $12.9 \%$, which was higher than other countries as well as other Iranian cities. Humidity and warm weather can be among the factors causing this difference in the incidence of postoperative infection at this treatment center compared with others. However, the conditions of the orthopedic operating room and the available facilities should also be taken into consideration.

\section{Conflict of Interest Disclosures}

The authors declare that they have no conflict of interests.

\section{Acknowledgements}

This article is the result of a dissertation on receiving a doctorate in medicine from the Faculty of Medicine of Hormozgan University of Medical Sciences, Iran. The researchers would like to acknowledge the efforts and cooperation of the medical records unit of Shahid Mohammadi Hospital.

\section{Ethical Statement}

The study received ethics approval from the Ethics Committee of Hormozgan University of Medical Sciences (IR.HUMS. REC.1397.036) and it complies with the statements of the Declaration of Helsinki.

\section{Authors' Contributions}

Conceptualization: AA; Study validation and supervision: SM; Data analysis and interpretation: AKHK, AHD; Writing and reviewing: MHA.

\section{Funding}

Hormozgan University of Medical Sciences funded the current study.

\section{Informed Consent}

Due to the retrospective design of the study the need for informed 
consent was waived for the participants.

\section{References}

1. Abdollahi AA, Rahmani H, Khodabakhshi B, Behnampour $\mathrm{N}$. Assessment of level of knowledge, attitude and practice of employed nurses to nosocomial infection in teaching hospitals of Golestan University of Medical Sciences (2000). J Gorgan Univ Med Sci. 2003;5(1):80-6. [Persian].

2. Oishi CS, Carrion WV, Hoaglund FT. Use of parenteral prophylactic antibiotics in clean orthopaedic surgery. A review of the literature. Clin Orthop Relat Res. 1993(296):249-55.

3. Darouiche RO. Treatment of infections associated with surgical implants. N Engl J Med. 2004;350(14):1422-9. doi: 10.1056/NEJMra035415.

4. Medeiros AC, Aires-Neto T, Azevedo GD, Vilar MJ, Pinheiro LA, Brandão-Neto J. Surgical site infection in a university hospital in northeast Brazil. Braz J Infect Dis. 2005;9(4):3104. doi: 10.1590/s1413-86702005000400007.

5. Owens CD, Stoessel K. Surgical site infections: epidemiology, microbiology and prevention. J Hosp Infect. 2008;70 Suppl 2:3-10. doi: 10.1016/s0195-6701(08)60017-1.

6. Berríos-Torres SI, Umscheid CA, Bratzler DW, Leas B, Stone EC, Kelz RR, et al. Centers for disease control and prevention guideline for the prevention of surgical site infection, 2017. JAMA Surg. 2017;152(8):784-91. doi: 10.1001/ jamasurg.2017.0904.

7. Badave GK, Kulkarni D. Biofilm producing multidrug resistant Acinetobacter baumannii: an emerging challenge. J Clin Diagn Res. 2015;9(1):DC08-10. doi: 10.7860/ jcdr/2015/11014.5398.

8. Castillo E, Mclsaac C, MacDougall B, Wilson D, Kohr R. Post-caesarean section surgical site infection surveillance using an online database and mobile phone technology. J Obstet Gynaecol Can. 2017;39(8):645-51.e1. doi: 10.1016/j. jogc.2016.12.037.

9. Khan MS, ur Rehman S, Ali MA, Sultan B, Sultan S. Infection in orthopedic implant surgery, its risk factors and outcome. J Ayub Med Coll Abbottabad. 2008;20(1):23-5.

10. de Carvalho RLR, Campos CC, Franco LMC, Rocha AM, Ercole FF. Incidence and risk factors for surgical site infection in general surgeries. Rev Lat Am Enfermagem. 2017;25:e2848. doi: 10.1590/1518-8345.1502.2848.

11. Najjar YW, Al-Wahsh ZM, Hamdan M, Saleh MY. Risk factors of orthopedic surgical site infection in Jordan: a prospective cohort study. Int J Surg Open. 2018;15:1-6. doi: 10.1016/j. ijso.2018.09.003.

12. Rütter JE, de Vries LS, van der Werken C. Intramedullary nailing of open femoral shaft fractures. Injury. 1994;25(7):41922. doi: 10.1016/0020-1383(94)90264-x.

13. Peivandi MT, Bahrehmand M, Ghayem Hasankhani E, Amel Farzad S. Unreamed intramedullary nailing in open femur fractures. Iranian Journal of Orthopaedic Surgery. 2007;5(3):146-51. [Persian].

14. Hojjat M, Karimyar JM, Keshaei N, Salehifard A. Assessment of the prevalence of post-operation orthopedic wound infection in the orthopedic ward of Motahari hospital (2009-2010). Iran J Surg. 2012;20(2):51-8. [Persian].

15. Khajemozafari J, Peivandi MT, Mostafavian Z, Meftah S. Comparison of close and open interlocking intramedullary nailing treatment of femoral shaft fractures. J Gorgan Univ Med Sci. 2013;15(2):1-7. [Persian].

16. Nowotarski PJ, Turen $\mathrm{CH}$, Brumback RJ, Scarboro JM. Conversion of external fixation to intramedullary nailing for fractures of the shaft of the femur in multiply injured patients. J Bone Joint Surg Am. 2000;82(6):781-8.

17. Noumi T, Yokoyama K, Ohtsuka H, Nakamura K, Itoman $M$. Intramedullary nailing for open fractures of the femoral shaft: evaluation of contributing factors on deep infection and nonunion using multivariate analysis. Injury. 2005;36(9):108593. doi: 10.1016/j.injury.2004.09.012.

18. Huntley SR, Lee S, Kalra R, McGwin G, Naranje S, Shah A. Associations between season and surgical site infections in orthopaedic foot and ankle surgery. Foot (Edinb). 2018;37:614. doi: 10.1016/j.foot.2018.04.008.

19. Azizi R, Jamshidi A, Taghipour MA. Effect of antibiotic prophylaxis in preventing wound infection in elective clean surgical procedures. Iran J Surg. 2007;15(1):108-13. [Persian].

20. Lhowe DW, Hansen ST. Immediate nailing of open fractures of the femoral shaft. J Bone Joint Surg Am. 1988;70(6):812-20.

21. O'Brien PJ, Meek RN, Powell JN, Blachut PA. Primary intramedullary nailing of open femoral shaft fractures. J Trauma. 1991;31(1):113-6. doi: 10.1097/00005373199101000-00022.

22. Williams MM, Askins V, Hinkes EW, Zych GA. Primary reamed intramedullary nailing of open femoral shaft fractures. Clin Orthop Relat Res. 1995(318):182-90.

23. Kundu ZS, Kamboj P, Sangwan S, Siwach R, Singh R, Walecha P. Management of open olecranon fractures using clampcum-compressor device. Indian J Orthop. 2009;43(1):50-4. doi: 10.4103/0019-5413.45324.

24. Mehdinassab SA, Sarrafan N, Eerabian R. Surgery in femoral shaft fractures in adults (a comparative study between plating and open interlocking nailing). Iranian Journal of Orthopaedic Surgery. 2011;9(3):124-32. [Persian].

25. Brumback RJ, Virkus WW. Intramedullary nailing of the femur: reamed versus nonreamed. J Am Acad Orthop Surg. 2000;8(2):83-90.

26. Riemer BL, Butterfield SL, Burke CJ 3rd, Mathews D. Immediate plate fixation of highly comminuted femoral diaphyseal fractures in blunt polytrauma patients. Orthopedics. 1992;15(8):907-16. 